Ambient Science, 2021: Vol. 08h(1); 15-19

DOI:10.21276/ambi.2021.08h.1.ta01

ambient SCIENCE

\title{
Change of Direction Run Tests: an Issue for SoccerTechnical Skills
}

\section{Çaglar Edis}

Faculty of Sports Science, Trabzon University, Trabzon, Akcaabat, TURKEY

Keywords: Small-sided game

The study was designed according to the rules and principles of the Declaration of Helsinki and approved by the University Ethics Committee (EGE.ETK. 19-1T/27). Written informed consent was obtained after an explanation of the nature and risks involved in participation in the experiment.

\section{Introduction:}

Soccer players performs high intensity actions between 150250 in the competitions (Carling \& Dupont, 2012).. In parallel, approximately 50 turns are performed by the soccers during the match (Withers, 1982). High-intensity activities, such as change of direction, can positively affect competition performance (Marcovic, 2007; Luhtanen \& Ekblom, 1994). High-intensity runs requiring different running patterns in competitions and training are affected by many physical features and changes of direction known as the most complex and most important movement pattern for the success of the physical and technical results (Young et al., 2002). However, in soccer games, soccer players must constantly perceive the positions of the opponents' soccer players, the opponent's goal and their teammates in the field, and as a result, change their direction and perform their technical skills. There are significant relationships between athletes' change of direction and short pass abilities (BenOunis, 2013). It has been revealed that elite soccer players perform more highintensity movements and perform more technical skills in parallel (Mohr et al., 2003). Besides this view, it can be thought that athletes should make decisions and run high intensity in order to better perform their technical skills.

The most frequent field of change of direction is the

\section{Abstract}

The purpose of this study was to investigate the relationships between the different change of directions (COD) performances and soccer technical skills performances. 18 amateur footballers participated in this study. The first week, players completed T-run, 5-0-5 run, Illinois COD test and Loughborough Soccer Passing Test (LSPT). In the second week, players completed 3 vs. 3 smallsided games (SSG). The peak heart rate (\%HR peak) and players' technical actions were recorded in the SSG. It has been revealed that the $\%$ HR peak of the players is different in every 4 sets. There were significant relationships between technical skill and \%HR peak values. While there was a statistical relationship between LSPT and soccer's technical skills. The results highlight that footballers may have to be complex COD tests such as the Illinois, 5-0-5 test and LSPT results for the success of the soccer technical skills. For soccer technical skills success players may have to be complex COD ability and trainers should take into consideration the development of the complex COD performances.

small-sided games, where soccer-specific developments are provided, and the small-sided games allow the development of COD performance with the endurance from the technical-tactical and physical skills in the soccer competition (Hammami, 2017; Impellizzeri et al., 2006). However, for small-sided games development of athletes, physical skills development and technical skills development. In researches where external factors of technical skill and small-sided games need to be examined like field dimensions affect technical skill performance (Kelly \& Drust, 2009), however, it is stated that there is a deficiency in examining the interactions of physical skills with technical skills by investigating the research similar to competition at the high intense game (Rostgaard, 2008). In addition, it has been stated that there are not enough of researches to understand technical skills, there is also no systematic results between technical skills and small-sided games in terms of internal factor (Hill-Haas, 2011). It is emphasized that athletes must have a proper level of internal preparedness to perform technical skills or get efficiency from some games (Lacome, 2018). In the literature, no research has been conducted to determine which COD skills from internal factors are related to soccer players' technical skills in small-sided games and highintensity game fields. For this reason, the purpose of this

*Corresponding Author: caglaredis@gmail.com 
research; the technical skills in the small-sided games of 3 vs. 3, which reflect the high intense parts of the soccer games of the different change of direction skills that the athletes have, and what change of direction the soccer players should change in terms of technical skills according to the results obtained from this study. And in light of this purpose, this study hypothesis was complex COD may be related to small-sided games technical performances.

\section{Materials and methods:}

A total of 18 soccer players participated in this research from the amateur league, athletes who were regularly trained 5 days a week and played an official competition for 1 day a week (age: 15.77 \pm 0.54 , height: $168.55 \pm 6.17$, weight: $69.46 \pm 5.98$, body mass index: $24.02 \pm 1.47$ ). The athletes included in the study were not having any injuries for a long time before the tests and participated regularly in their team training. During all tests, the tests of athletes who had problems with any injury or skeletal system were eliminated and the study was completed with athletes who completed the tests with maximum effort.

The research was carried out with the evaluation of acute performances in the last 2 weeks of the preparation season of soccer players. Dynamic warming procedure was performed on soccer players before all tests procedure. Ttest and 5-0-5 tests were performed on the day after the 1stweek recovery training. In the days following these tests, the Illinois test and LSPT were performed consecutively. In the 2nd week, on the next day after the recovery training, 3 vs. 3 small-sided games of the athletes were performed. The verbal motivation was provided to outside athletes by coaches in order to obtain full efficiency from soccer players' COD skills and SSG.

The measurements height, body mass, body mass indices (BMI) and body fat rates of the athletes were performed on a day before the study. The height and body mass of the athletes were measured with the calibrated Seca stadiometer (Holtain Ltd., UK) without shoes and with shorts and T-shirts. BMI was calculated as "mass $(\mathrm{kg}) /$ length $(\mathrm{m})_{2}$. Body fat ratio was estimated using Harpender caliper using skinfold measurement and only data from the right side of the body. In this measurement, the data obtained from the 7-region $(\mathrm{mm})$ of the body (triceps, subscapular, axilla, chest, suprailiac, abdomen, and thigh) were calculated using the equation created for men (Durnin \& Rahaman, 1967) and the estimated body density was calculated using the data obtained from Siri (1956), body fat ratios were revealed.

All Change of Direction tests were measured in the synthetic field, where athletes regularly train. Illinois test, T-test and $5^{-0}-5$ test were measured as specified in the literature (Hoffman, 2006; Semenick, 1990; Draper, 1985). Before each test, athletes were ready to start the test track 1 meter before the timer. Athletes waited in front of the test gate in the position where the athlete felt most comfortable. Then the athlete started the test by passing through the start gate in his reaction at any time. Tests were carried out with passive rest each test and 3 repetitions.

Soccer short passing technique test was measured to determine the technical level of the athletes. The athlete was started with the first contact with the ball in the middle of the field. The first pass started with the athlete sending the ball to a goal of his own, but later passes were sending to the colours the researcher said, and testing continued. The same researcher performed the targeting in every athlete for reliability. During the test, 16 passes were offered, with 4 passes per colour, with the coach's instructions. When the pass offered by the athlete to the 16th colour reached the target, the time was stopped and the test was ended. As a result of the test, for the additional time of over 43 seconds, $\mathrm{a}+1$ second penalty was added to the athlete's data set for each additional time (Le Moal, 2014). The tests were measured by 2 experienced and expert coaches. While one of the coaches said the colours that the athlete should pass, the other coach checked the time with the stopwatch and recorded the mistake of the rules. The test was measured with a total of 3 sets and 5 minutes of passive rest between each set. The test data was added to the SPSS analyzes in terms of time.

After the week of all tests, SSG was performed with field size: $20 \times 30=600 \mathrm{~m} 2(1: 100 \mathrm{~m} 2$ pitch ratio per player), the number of players: 3 versus 3, playing time: 3:00 min, rest time: $3: 00$ min and 4 repetitions. The matches of the athletes in the games were determined by the randomization method. All games were recorded with a video camera (Sony Handycam. DCR-SR15), was positioned at a height of 2 meters in a parallel line corresponding to the middle of the playing field. The shots (successful-unsuccessful), passes (successfulunsuccessful), dribble past (successful-unsuccessful), ball losses and ball-winning numbers were then recorded in the computer and then transfer into the data set.

Descriptive statistics of the test data were expressed as mean \pm standard deviation. Whether the data conform to the normal distribution assumption was examined according to the results of the Shapiro Wilk test. Wilcoxon's Signed Rank test was used in sets that did not show the normal distribution in comparisons between the maximal heart rate numbers of the 4 sets. Pair Sample-T test was used for the differences between the sets with normal distribution. In addition, the effects sizes between the data were calculated in the comparison analysis. Comparisons result of the SSG's peak heart rate was assessed by calculating Cohen's d effect size (Cohen, 1998) and Wilcoxon's effect sizes were calculated as follows: $=\mathrm{Z} / \mathrm{V}$ $\mathrm{N}$. The relationships between COD, LSPT and SSG performance were analyzed using the Correlation Analysis $(\mathrm{r})$, with the level of statistical significance set at $\mathrm{p}<0.05$ 


\section{TECHNOSCIENCE ARTICLE}

in SPSS for Windows, version 21.o (SPSS, Inc. Chicago, IL).

\section{Results:}

Table 1. Descriptive statistic $(\mathrm{N}=18)$

\begin{tabular}{lllll}
\hline Performance Test & Min. & Max. & Mean & Std. Dev. \\
\hline T-test & 9.34 & 10.57 & 9.8817 & .317 \\
505agility test & 7.78 & 8.81 & 8.4072 & .290 \\
Illinois agility test & 14.53 & 16.43 & 15.6172 & .474 \\
LSPT & 33.07 & 74.16 & 51.0956 & 10.798 \\
\hline
\end{tabular}

LSPT: Loughborough Soccer Passing Test.

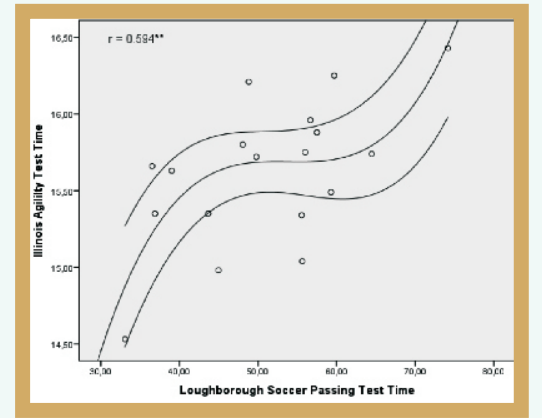

Figüre-1: Correlations result between the Illinois agility test time and LSPT time.

Figüre-1: While there were strong relationships between the LSPT and Illinois test $\left(\mathrm{r}=0.594^{* *}\right)$, the statistical relationship wasn't found between the T-test, 5-0-5 tests and the LSPT ( $r$ values 0.09 to 0.298$)$.

Especially, there was a strong statistical relationship between $5^{-0}-5$ test time and unsuccessful pass $\left(\mathrm{r}=.612^{* *}\right)$ and successful shots $\left(r=.641^{* *}\right)$. In addition, there was a significant relationship between the T-test in Set 2 and the number of unsuccessful passes $\left(\mathrm{r}=0.597^{* *}\right)$. Results related to other data are shown in detail in Table-2. and 3. The 3 rd and 4th sets of games and the total technical skills numbers are not statistically significant with LSPT and COD skills (rvalues between 0.04 and 0.460 ).

Table 2. Correlation analyses between SSG technical skills. LSPT and COD. (1st Set)

\begin{tabular}{llllll}
\hline & & LSPT & $\begin{array}{l}\text { T-test } \\
\text { test }\end{array}$ & $\begin{array}{l}\text { 505 agility } \\
\text { agility test }\end{array}$ & Illionis \\
\hline Pass & Success & -.219 & -.057 & -.191 & $-.477^{*}$ \\
& Unsuccess & $.497^{*}$ & .196 & $.612^{* *}$ & $.560^{*}$ \\
Dribble & Success & -.349 & -.299 & -.319 & -.169 \\
past & Unsuccess & .248 & -.045 & $-.470^{*}$ & .105 \\
Dribble & Success & $-.471^{*}$ & -.115 & $-.641^{* *}$ & -.383 \\
past & Unsuccess & .148 & -.380 & .218 & -.121 \\
& Ball lose & .375 & -.006 & -.091 & $.569^{*}$ \\
& Ball win & .053 & -.041 & .246 & -.015 \\
\hline
\end{tabular}

$\mathrm{p}=0.05^{*}$; LSPT: Loughborough soccer passing test

The comparison of the $\% \mathrm{Hr}_{\text {peak }}$ of the small-sided games shows graph 1 . Between the 1st set and the 2nd set $(\mathrm{p}=$ $0.029, \mathrm{z}=-2.180, \mathrm{Es}=-0.37387)$ and a statistical difference was found between the ist set and the 3 rd set ( $\mathrm{p}=0.069, \mathrm{t}=$ 1.945, Cohen $\mathrm{d}=-0.0589405, \mathrm{r}=-0.0294575)$ there were also statistical differences between the 3 rd and 4 th set $(p=0.092$, $t=1.785$, Cohen $d=-0.0290125, r=-0.0145047)$. As for the
Ambient Science, 2021: Vol. 08h(1); 15-19 DOI:10.21276/ambi.2021.08h.1.ta01

heart rate in the games and the technical skill, there are relations between the $\% \mathrm{HR}_{\text {peak }}$ during the game and the successful pass $\left(r=0.527^{*}\right)$ in the games in the first set. There was no significance in other statistical correlations in this set. In the second set, there were statistically significant relationships between $\% \mathrm{HR}_{\text {peak }}$ and the number of unsuccessful shots $\left(\mathrm{r}=0.5 \mathrm{O2}^{*}\right)$ and the number of unsuccessful passes $\left(\mathrm{r}=0.525^{*}\right)$, while no correlations were found between other results ( $\mathrm{r}$ value between 0.31 and o.358). In the third set, there are related results between $\% \mathrm{HR}_{\text {peak }}$ and the number of ball wins $\left(\mathrm{r}=0.613^{* *}\right)$ and the number of unsuccessful shots $\left(\mathrm{r}=0.538^{*}\right)$, while other results are not significant correlations ( $\mathrm{r}$ value is between 0.132 and 0.436 ). In the fourth set, there was no statistical relationship between $\% \mathrm{HR}_{\text {peak }}$ and the number of technical skills (rvalue between 0.17 and 0.370 ).

Table 3. Correlation analyses between SSG technical skills. LSPT and COD.

\begin{tabular}{llllll}
\hline & & LSPT & T-test & $\begin{array}{l}505 \text { agility } \\
\text { test }\end{array}$ & $\begin{array}{l}\text { Illionis } \\
\text { agility test }\end{array}$ \\
\hline Pass & Success & -.070 & .029 & -.195 & -.260 \\
& Unsuccess & $-.493^{*}$ & $.597^{* *}$ & -.108 & -.330 \\
Dribble & Success & -.269 & -.207 & -.250 & -.195 \\
past & Unsuccess & -.086 & -.436 & -.300 & -.183 \\
Shot & Success & .102 & .116 & .067 & .133 \\
& Unsuccess & -.023 & .271 & -.352 & .095 \\
& Ball lose & $-.539^{*}$ & -.158 & -.326 & $.519^{*}$ \\
& Ball win & -.057 & .086 & .074 & -.447 \\
\hline
\end{tabular}

$\mathrm{p}=0.05^{*}$; LSPT: Loughborough soccer passing test.

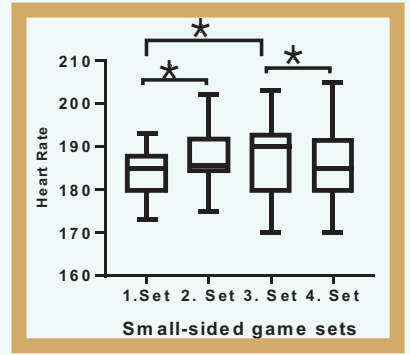

Figure-2: Descriptive of peak heart rate and comparison of the sets peak heart rate.

In this study, no significant correlations was found in the correlation analysis with the technical performance data obtained in the sum of 4 sets of small-sided games and the COD and LSPT tests results

\section{Discussion:}

In the main results of the study, while 5-0-5 tests, Illinois tests and LSPT were found in the first set, there were significant relationships between the T-test and second set technical skills. Apart from the games, there was a relationship between the LSPT and the Illinois test times. Relationships have also between the heart rate of soccer players and technical skill in games.

In small-sided games, different methods were used to determine the intensity of the game. One of these methods 
was the heart rate. It was stated that $\% \mathrm{HR}_{\text {peak }}$ reserves were played with $81.5 \%$ of the games played as $3 \mathrm{Vs} .3$ in the games (Dellal et al., 2012). It shows that HRmax is played with $89.5 \%$ in games played as 3 vs. 3 in a different study (Aguiar et al., 2013). Williams \& Owen (2007) obtained the heart rate as $171 \pm 11$ in 3 vs. 3 player games played on an area of $30 \times 25$ meters. As seen in the 3 vs. 3 player games, the intensity of the game is that the heart rates were over $80 \%$. In this research, similar to the research, the heart rate was obtained in 3 vs. 3 games with $184.05 \pm 5.59$ in 1 set, $188.33 \pm 7.55$ in 2 sets, $188.66 \pm 9.54$ in 3 sets and $185.77 \pm 10.35$ $\% \mathrm{HR}_{\text {peak }}$ in 4 sets.

The Small-sided games for a long training period of time were in the direction that increases the agility performance of athletes (Hammami et al., 2017). For this reason, they stated that in small-sided games, soccer players improved their agility performance due to their ability to create space in a very short time, pass their teammates among an opponent number of players, perceive against opponent pressure in a very short time and they play soccer in small area technical and physical performance capacity by making decisions in a short time accordingly. COD and agility skills also seem to be one of the most important skills among research subjects, because this value was very critical for competition performance (Mujika et al., 2009). What different from this skill from other physical fitness levels was that muscle strength, balance, eccentric strength, concentric strength, perception and decision-making levels are related to this skill (Sheppard \& Young, 2006; Spiteri et al., 2014; Sekulic et al., 2013). With the global positioning system, the speed of the games is frequently followed in Small-sided games (Dellal et al., 2011). It is stated that the athletes playing high-level soccer have better running performance (Ali, 2011). In this research, in the first two sets of the game, significant statistical relationships were found between the 5-0-5 test, Illinois test and LSPT test scores of the athlete's technical skill results. It suggests that athletes would not affect by fatigue in the first sets (statistically significant difference between the $\% \mathrm{HR}_{\text {peak }}$ of the sets) in the first two sets, and as a result, the athletes mostly COD and agility skills and technical skills. In support of this situation, in the games of the third set, it is supported that athletes have a significant relationship with the ball-winning skills of their heart rate, but the number of unsuccessful shots increases with increasing heart rate. Because, it can be said that the athletes' contact with the opponent to win the ball, intervene by sliding, is due to the possibility of demanding more energy than the moderate intensity in the small-sided games. In the previous research, it was clearly stated that the fatigue index affects the technical performance of athletes, and the fatigue index impairment the athlete's shooting performance (Rostgaard et al., 2008). In this research, the occurrence of similar conditions with the heart rate seems to support each other with the information in the literature.

LSPT test is used to measure the effectiveness of short pass skills of athletes. This test involves athletes' ability to perceive, make decisions, and complete the test in a short time, such as agility and COD tests, and perform technical skills correctly (BenOunis et al., 2013; Ali et al., 2007). In the study investigating the relationship between LSPT and COD skills, it is concluded that the athletes who successfully completed this test also completed their COD skills in a short time (Hammami et al., 2017). In this study, there is a significant relationship between the Illinois test and the LSPT test, and the result of the research was similar to the literature. In the Illinois test, athletes must complete the test by running with the ball through many cones. In addition, the fact that there are many sudden stops, accelerations and changes of direction in this test and many changes of direction in the LSPT test explain the relations between each other.

\section{Conclusion:}

In the evaluation of the COD measurements of the athletes, the COD skills associated with soccer were examined as Illinois and 5-0-5 tests. In addition to this, it can be thought that $\mathrm{T}$-test runs do not contain many relationships and that more complex gains in soccer such as Illinois agility and 5-05 tests can provide more positive gains for athletes to achieve more successful results from games. Complex COD skills need to be developed for athletes to better perform technical skills in areas where the game is small on the soccer field.

\section{References:}

Aguiar, M., Gonçalves, B., Botelho, G., Lemmink, K., \& Sampaio, J. (2015). Footballers' movement behaviour during 2-, 3-, 4-and 5-a-side small-sided games. J. Sports Sci., 33(12):1259-1266.

Aguiar, M.V., Botelho, G.M., Gonçalves, B.S., \& Sampaio, J.E. (2013): Physiological responses and activity profiles of football small-sided games. J. St. Cond. Res., 27(5):1287-1294.

Ali, A. (2011): Measuring soccer skill performance: a review. Scandinavian J. Med. Sci. Sport., 21(2):170-183.

Ali, A., Williams, C., Hulse, M., Strudwick, A., Reddin, J., Howarth, L., Eldred, J., Hirst, M. \& McGregor, S. (2007): Reliability and validity of two tests of soccer skill. J. Sport. Sci., 25(13):1461-1470.

BenOunis, O., BenAbderrahman, A., Karim Chamari, A.A., BenBrahim, M., Hammouda, A., Hammami, M.A., \& Zouhal, H. (2013): Association of short-passing ability with athletic performances in youth soccer players. Asian J. Sport. Med., $4(1): 41$.

Carling, C., Le Gall, F., \& Dupont, G. (2012). Analysis of repeated high-intensity running performance in professional soccer. $J$. Sports $S_{c i .}$ 30(4), 325-336..

Cohen, J. (1998): Statistical Power Analysis for the Behavioral Sciences. Pub. by: Routledge; 2nd edition. P. 400.

Durnin, J.V.G.A., \& Rahaman, M.M. (1967): The assessment of the amount of fat in the human body from measurements of 


\section{TECHNOSCIENCE ARTICLE}

skinfold thickness. Br.J. Nutr., 21(3):681-689.

Dellal, A., Drust, B., \& Lago-Penas, C. (2012): Variation of activity demands in small-sided soccer games. Int. J. Sports Med., 33(05):370-375.

Dellal, A., Hill-Haas, S., Lago-Penas, C., \& Chamari, K. (2011): Small-sided games in soccer: amateur vs. professional players' physiological responses, physical, and technical activities. J. St. Cond. Res., 25(9):2371-2381.

Dellal, A., Chamari, K., Pintus, A., Girard, O., Cotte, T., \& Keller, D. (2008). Heart rate responses during small-sided games and short intermittent running training in elite soccer players: a comparative study. J. St. Cond. Res., 22(5):1449-1457.

Draper, J.A. (1985): The 505 test: A test for agility in horizontal plane. Aust.J. Sci. Med. Sport, 17(1):15-18.

Hoffman, J. (2006): Norms for Fitness, Performance, and Health. Pub. by: Human Kinetics. P. 221.

Hammami, A., Gabbett, T. J., Slimani, M., \& Bouhlel, E. (2017): Does small-sided games training improve physical-fitness and specific skills for team sports? A systematic review with meta-analysis. L. Sports Med. Phys. Fitness, 58(10):1446-1455.

Hill-Haas, S.V., Dawson, B., Impellizzeri, F.M., \& Coutts, A.J. (2011): Physiology of small-sided games training in football. Sports Med., 41(3):199-220.

Impellizzeri, F.M., Marcora, S.M., Castagna, C., Reilly, T., Sassi, A., Iaia, F.M., \& Rampinini, E. (2006): Physiological and performance effects of generic versus specific aerobic training in soccer players. Int. J. Sports Med., 27(06):483-492.

Köklü, Y., Albayrak, M., Keysan, H., Alemdaroglu, U., \& Dellal, A. (2013): Improvement of the physical conditioning of young soccer players by playing small-sided games on different pitch size-special reference to physiological responses. Kinesiol.: Int.J. Fund. App. Kinesiol., 45(1):41-47.

Kelly, D.M., \& Drust, B. (2009): The effect of pitch dimensions on heart rate responses and technical demands of small-sided soccer games in elite players. J. Sci. Med. Sport., 12(4):475-479.

Luhtanen, P., \& Ekblom, B. (1994): Football (Soccer) Handbook of Sports Medicine and Science. Pub. by: Wiley. P. 240.

Le Moal, E., Rué, O., Ajmol, A., Abderrahman, A.B., Hammami, M.A., Ounis, O.B., Kebsi, W. \& Zouhal, H. (2014): Validation of the Loughborough soccer passing test in young soccer players. J. St. Cond. Res., 28(5):1418-1426.

Lacome, M., Simpson, B.M., Cholley, Y., Lambert, P., \& Buchheit, M. (2018). Small-sided games in elite soccer: Does one size fit all? Int.J. Sport. Physiol. Perform., 13 (5): 568-576.
Ambient Science, 2021: Vol. 08h(1); 15-19 DOI:10.21276/ambi.2021.08h.1.ta01

Marcovic, G. (2007): Poor relationship between strength and power qualities and agility performance. L. Sport. Med. Phys. Fitn., 47(3): 276.

Mohr, M., Krustrup, P., \& Bangsbo, J. (2003): Match performance of high-standard soccer players with special reference to development of fatigue. J. Sport. Sci., 21(7):519-528.

Mujika, I., Santisteban, J., Impellizzeri, F.M., \& Castagna, C. (2009). Fitness determinants of success in men's and women's football.JSport. Sci., 27(2):107-114.

Owen, A.L., Wong, D.P., Paul, D., \& Dellal, A. (2012): Effects of a periodized small-sided game training intervention on physical performance in elite professional soccer. J. St. Cond. Res., 26(10):2748-2754.

Rostgaard, T., Iaia, F.M., Simonsen, D.S., \& Bangsbo, J. (2008): A test to evaluate the physical impact on technical performance in soccer. L. St. Cond. Res., 22(1):283-292.

Sheppard, J.M., \& Young, W.B. (2006): Agility literature review: Classifications, training and testing. L. Sport Sci., 24(9):919932.

Siri, W.E. (1956): Body composition from fluid spaces and density: analysis of methods. Nutrition, 9(5):480-491

Semenick, D. (1990): Tests and measurements: The T-test. $\underline{\text { St. }}$ Cond. I., 12(1):36-37.

Spiteri, T., Nimphius, S., Hart, N.H., Specos, C., Sheppard, J.M., \& Newton, R.U. (2014): Contribution of strength characteristics to change of direction and agility performance in female basketball athletes. J. St. Cond. Res., 28(9):2415-2423.

Sekulic, D., Spasic, M., Mirkov, D., Cavar, M., \& Sattler, T. (2013). Gender-specific influences of balance, speed, and power on agility performance. J. St. Cond. Res., 27(3):802-811.

Withers, R.T. (1982). Match analyses of Australian professional soccer players. J. Hum. Move. Stud., 8:159-176.

Williams, K., \& Owen, A. (2007): The impact of player numbers on the physiological responses to small-sided games. L. Sport. Sci. Med., 6(Suppl 10):100.

Young, W.B., James, R., \& Montgomery, I. (2002): Is muscle power related to running speed with changes of direction? J. Sport. Med. Phys. Fitn., 42(3):282-288. 